\title{
TATA KELOLA PERUSAHAAN, PERTANGGUNGJAWABAN LINGKUNGAN, DAN NILAI PERUSAHAAN STUDI KASUS DI SEKTOR MANUFAKTUR DAN PERTAMBANGAN INDONESIA
}

\author{
Rintan Nuzul Ainy \\ Universitas Ahmad Dahlan \\ ainy-rintan@yahoo.com
}

\begin{abstract}
This study examines the relationship of corporate governance, environmental responsibility, and firm value in Indonesia. This study extends the literature by considers the role of environmental responsibility in the indirect relationship of corporate governance and firm value. The environmental responsibility data index is calculated by doing a content analysis of company's annual and sustainability report of 2013. The other data is obtained from OSIRIS database and Bursa Efek Indonesia.

The result shows that voluntary activities such environmental responsibility effects the firm value. This study shows that there is no indirect relationship between corporate governance, environmental responsibility, and firm value in Indonesia.
\end{abstract}

Keywords: Corporate Governance, Environmental Responsibility, Firm Value.

\section{PENDAHULUAN}

Dewasa ini, negara berkembang menjadi tujuan investasi yang menarik bagi investor asing. Survei yang dilakukan EIRIS dalam Emerging Market Disclosure Project (EMDP) menunjukkan adanya peningkatan investasi asing di negara berkembang sejak tahun 2009. Peningkatan investasi ini berdampak positif pada kondisi ekonomi negara yang bersangkutan. Namun, peningkatan investasi tersebut dapat berdampak negatif pada lingkungan terkait dengan semakin besarnya eksploitasi sumber daya alam. Semakin besar dampak operasi perusahaan pada lingkungan, semakin besar pula pertanggungjawaban lingkungan yang dilakukan perusahaan.

Pertanggungjawaban lingkungan perusahaan di Indonesia masih bersifat sukarela. Belum adanya peraturan yang mengharuskan inilah yang menyebabkan tidak semua perusahaan melakukan pertanggungjawaban lingkungan. Salah satu faktor yang memengaruhi keputusan perusahaan melakukan pertanggungjawaban lingkungan adalah tata kelola perusahaan. Semakin efektif tata kelola suatu perusahaan, semakin besar kecenderungan perusahaan tersebut melakukan pertanggungjawaban lingkungan (Rao, Tilt, dan Lester, 2012).

Selain faktor pendukung seperti tata kelola perusahaan yang efektif, keputusan perusahaan melakukan pertanggungjawaban sukarela juga dipengaruhi oleh manfaat yang diperoleh perusahaan. Penelitian-penelitian sebelumnya menunjukkan bahwa perusahaan yang melakukan pertanggungjawaban ling-kungan berkinerja lebih baik (Al-Tuwaijri, Christensen, dan Hughes, 2004; Jo dan Harjoto, 2012). Pertanggungjawaban lingkungan dianggap dapat mengurangi konflik kepentingan yang terjadi antara manajer dan 
pemangku kepentingan, sehingga berpengaruh pada peningkatan nilai perusahaan (Jo dan Harjoto, 2012).

Penelitian ini ingin menguji pola hubungan tata kelola perusahaan, pertanggungjawaban lingkungan, dan nilai perusahaan di Indonesia. Jo dan Harjoto (2012) menunjukkan bahwa pertanggungjawaban lingkungan memediasi hubungan tatakelola dannilai perusahaan dinegara maju. Tsamenyi, Enninful-Adu, dan Onumah (2007) menyatakan bahwa negara berkembang memiliki karakteristik dan permasalahan yang berbeda. Peneliti menguji hubungan tata kelola perusahaan, pertanggungjawaban lingkungan, dan nilai perusahaan dengan mempertimbangkan permasalahan tata kelola di Indonesia, yaitu struktur kepemilikan yang terkonsentrasi dan kualitas audit.

\section{REVIEW LITERATUR DAN HIPOTESIS}

\section{Teori Keagenan (Agency Theory)}

Teori keagenan mendeskripsikan hubungan pemangku kepentingan (pemegang saham) sebagai prinsipal dan manajer sebagai agen. Prinsipal mendelegasikan wewenang pengambilan keputusan atas nama mereka kepada agen (Jensen dan Meckling, 1976). Permasalahan yang muncul akibat hubungan prinsipal-agen ini adalah konflik kepentingan, yaitu agen tidak selalu mengambil keputusan sesuai dengan kepentingan prinsipal. Teori ini juga menggambarkan terdapat informasi asimetri antara agen dan prinsipal. Informasi asimetri muncul ketika agen memiliki informasi yang lebih dibanding prinsipal dan pemangku kepentingan lainnya. Informasi asimetri ini berkurang jika pihak agen melakukan pengungkapan informasi. Tata kelola perusahaan dianggap dapat mengawasi dan mengontrol agar agen tidak melakukan perilaku moral hazard dan melakukan pengungkapan (Rao dkk., 2012).
Menurunnya tingkat informasi asimetri kemudian meningkatkan nilai perusahaan.

\section{Teori Pemangku Kepentingan (Stakeholder Theory)}

Teori pemangku kepentingan menyatakan bahwa perusahaan tidak dapat beroperasi untuk kepentingan mereka sendiri, namun juga harus dapat memberikan manfaat bagi seluruh pemangku kepentingan. Perusahaan perlu mengelola hubungan baik dengan seluruh pihak yang berkepntingan, yaitu kelompok atau individu yang yang dapat mempengaruhi dan dipengaruhi oleh pencapaian tujuan dan kelangsungan hidup perusahaan (Donaldson dan Preston, 1995; Freeman dan Phillips, 2002; Jones, 1995). Tata kelola perusahaan yang baik dapat mendorong pemenuhan kepentingan, salah satunya pertanggungjawaban lingkungan, yang nantinya dapat berdampak pada peningkatan nilai perusahaan.

\section{Teori Legitimasi (Legitimacy Theory)}

Dasar teori legitimasi adalah perusahaan memiliki kontrak sosial dengan masyarakat dimana perusahaan tersebut beroperasi dan menggunakan sumber dayanya. Teori legitimasi menyatakan bahwa perusahaan tidak dapat dipisahkan dari konteks sosial; perusahaan tidak dapat hanya memperhatikan kepentingan investor, tetapi juga secara umum harus memperhatikan kepentingan publik; perusahaan memiliki kontrak sosila dengan lingkungan di sekitarnya (Deegan dan Rankin, 1997; Holder-webb, Cohen, Nath, dan Wood, 2009). Pertanggungjawaban lingkungan yang dilakukan oleh perusahaan merupakan suatu bentuk pertanggungjawaban perusahaan atas penggunaan sumber daya yang ada. Pertanggungjawaban kontrak sosial tersebut dapat terpenuhi jika didukung oleh sistem tata kelola yang baik, yang nantinya dapat berdampak pada nilai perusahaan. 


\section{Hubungan Antara Tata Kelola Perusahaan dan Pertanggungjawaban Lingkungan Perusahaan}

Berdasarkan teori pemangku kepentingan, terdapat hubungan positif antara tata kelola dan aktivitas pertanggungjawaban sosial dan lingkungan. Mendukung teori tersebut, Spitzeck (2009) menyatakan bahwa tata kelola perusahaan yang baik akan menuntut manajer untuk memperhatikan kepentingan seluruh pemangku kepentingan. Teori legitimasi pun menyatakan bahwa perusahaan tidak dapat dipisahkan dari konteks sosial; perusahaan memiliki kontrak sosial dengan lingkungan di sekitarnya (Holderwebb, Cohen, Nath, dan Wood, 2009). Perusahaan meningkatkan aktivitas sosial mereka, salah satunya adalah pertanggungjawaban lingkungan, jika didukung dengan sistem tata kelola yang baik.

Menurut La Porta, Lopez-de-Silanes, dan Shleifer (1999), permasalahan yang terjadi di negara berkembang adalah permasalahan keagenan antara pemilik mayoritas dan minoritas. Salah satu karakteristik perusahaan Indonesia adalah struktur kepemilikan yang terkonsentrasi (Choi, 2003). Struktur kepemilikan perusahaan yang terkonsentrasi mengindikasikan bahwa adanya gap antara pemilik mayoritas dan minoritas. Lakhal (2005) dan Rao dkk. (2012) menyatakan bahwa tata kelola perusahaan yang efektif (baik) dapat mengurangi permasalahan keagenan yang terjadi di perusahaan serta mendorong untuk melakukan aktivitas yang bersifat sukarela (voluntary).

Ketika struktur kepemilikan perusahaan terkonsentrasi, peluang perusahaan untuk dimiliki oleh publik semakin rendah, sehingga isu pertanggungjawaban kepada publik (misal pertanggungjawaban lingkungan) pun semakin rendah (Ghazali, 2007; Tsamenyi dkk., 2007). Semakin terkonsentrasi struktur kepemilikan suatu perusahaan, komposisi kepemilikan publik kecil, pengawasan publik terhadap perusahaan tersebut pun rendah, sehingga kecenderungan perusahaan untuk melakukan pertanggungjawaban lingkungan pun semakin rendah. Penelitian sebelumnya, R.M. Haniffa dan Cooke (2005); dan Jo dan Harjoto (2011, 2012), juga menunjukkan hubungan yang berbanding terbalik antara struktur kepemilikan perusahaan yang terkonsentrasi dan pertanggungjawaban lingkungan.

$\mathbf{H}_{\mathbf{1}}$ : Konsentrasi kepemilikan berpengaruh negatif pada pertanggungjawaban lingkungan perusahaan.

Kualitas audit merupakan salah satu tata kelola perusahaan Indonesia yang masih membutuhkan perhatian (KNKG, 2006). Penelitian Said, Hj Zainuddin, dan Haron (2009) menunjukkan bahwa komite audit berperan dalam meningkatkan kualitas laporan keuangan. Hal yang sama juga diungkapkan oleh McMullen dan Raghunandan (1996) dan Wright (1996). Mereka menemukan bahwa komite audit independen memiliki peranan dalam meningkatkan kualitas laporan keuangan.

Komite audit independen juga berpengaruh dalam pengambilan keputusan perusahan untuk melakukan pertanggungjawaban lingkungan. Hubungan positif antara keberadaan komite audit independen dan aktivitas sukarela perusahaan ditunjukkan dalam penelitian Camfferman dan Cooke (2002) dan Haposoro (2012). Logika yang dapat dibangun dari hubungan tersebut ialah semakin tinggi komposisi komite audit independen dapat mengurangi permasalahan keagenan (berdasarkan teori keagenan) sehingga mempengaruhi kontrol internal, termasuk keputusan perusahaan melakukan pertanggungjawaban lingkungan.

$\begin{aligned} & \mathbf{H}_{2}: \text { Kualitas audit berpengaruh positif } \\ & \text { pada pertanggungjawaban lingkungan } \\ & \text { perusahaan. }\end{aligned}$




\section{Hubungan Antara Tata Kelola Perusahaan dan Nilai Perusahaan}

Berdasarkan teori keagenan, masalah keagenan muncul karena adanya konflik kepentingan antara dua pihak, misal antara prinsipal dan manajer atau antara pemegang saham mayoritas dan minoritas (Jensen dan Meckling, 1976). Mekanisme tata kelola merupakan media untuk mengurangi konflik kepentingan antar para pemangku kepentingan (Shleifer dan Vishny, 1997).

Penelitian sebelumnya menunjukkan bahwa konflik keagenan yang terjadi di perusahaan akan mempengaruhi kinerja perusahaan (Dey, 2008; Siagian, Siregar, dan Rahadian, 2013). Konflik keagenan yang terjadi di negara berkembang adalah antara pemegang saham mayoritas dan minoritas (La Porta dkk., 1999). Permasalahan keagenan terjadi lebih tinggi di perusahaan dengan struktur kepemilikan terkonsentrasi dibanding perusahaan dengan kepemilikan tersebar (Dey, 2008; Ghazali, 2007; Tsamenyi dkk., 2007). Kepemilikan saham yang tersebar dapat menjadi salah satu mekanisme untuk mengurangi biaya keagenan sehingga nilai perusahaan dapat meningkat.

\section{$\mathbf{H}_{3}$ : Konsentrasi kepemilikan berpengaruh negatif pada nilai perusahaan.}

Komite audit independen dapat berfungsi sebagai pengawas kinerja agen, pengamat sistem pengendalian internal, dan penguji atas kredibilitas informasi akuntansi yang disediakan oleh agen (manajer) (Siallagan dan Machfoedz, 2006). Keberadaan audit independen dengan segala fungsinya tersebut bertujuan untuk meningkatkan nilai perusahaan. Pengawasan dan pengendalian dilakukan untuk mencegah perilaku moral hazard dari manajer, pengujian informasi akuntansi dilakukan agar informasi yang dihasilkan dapat dipercaya dan dapat dipertanggungjawabkan.
Hubungan komite audit independen dan nilai perusahaan telah dibuktikan di beberapa penelitian terdahulu. Klein (2002) membuktikan hubungan tersebut menggunakan kualitas laba sebagai indikator nilai perusahaan. Siallagan dan Machfoedz (2006) membuktikan bahwa terdapat hubungan positif antara keberadaan komite audit independen dan nilai perusahaan dilihat dari rendahnya manajemen laba dan tingginya kualitas laba suatu perusahaan

$\mathbf{H}_{4}$ : Kualitas audit berpengaruh positif pada nilai perusahaan.

\section{Hubungan Antara Pertanggungjawaban Lingkungan dan Nilai Perusahaan}

Teori pemangku kepentingan dan legitimasi telah menyatakan bahwa perusahaan tidak dapat dipisahkan dari konteks sosial. Mereka memiliki tanggung jawab untuk dapat memberikan manfaat tidak hanya untuk pemegang saham, namun juga untuk seluruh pemangku kepentingan. Tanggung jawab ini harus mereka penuhi agar memperoleh dukungan dari lingkungan sosial untuk dapat terus beroperasi (Freeman dan Phillips, 2002; Holder-webb dkk., 2009). Salah satu bentuk nyata perwujudan kedua teori ini adalah pertanggungjawaban lingkungan perusahaan. Pertanggungjawaban lingkungan ini merupakan sinyal dari perusahaan bahwa mereka telah memenuhi tanggungjawab sosialnya, memberikan manfaat bagi seluruh pemangku kepentingan, dan pengharapan untuk dapat dinilai dengan baik sehingga dapat terus beroperasi.

Nilai perusahaan diketahui sebagai pengukuran ekonomi yang mencerminkan nilai bisnis secara keseluruhan yang dialokasikan kepada pemegang saham dan pemegang surat hutang perusahaan (Malik, 2014). Penelitian sebelumnya menunjukkan bahwa terdapat hubungan positif antara pertanggungjawaban lingkungan dan nilai perusahaan. Perusahaan yang melakukan pertanggungjawaban lingkungan 
cenderung memiliki berkinerja lebih baik (dinilai lebih baik) (Al-Tuwaijri dkk., 2004; Jo dan Harjoto, 2011, 2012). Suatu meta-analysis terkait hubungan tersebut telah dilakukan oleh Moser dan Martin (2012) dan menghasilkan kesimpulan hubungan positif antara pertanggungjawaban sosial dan lingkungan dan kinerja perusahaan.

$\mathbf{H}_{5}$ : Pertanggungjawaban lingkungan perusahaan berpengaruh positif pada nilai perusahaan.

Hubungan Tata Kelola Perusahaan, Pertanggungjawaban Lingkungan, dan Nilai Perusahaan

Hasil penelitian Jo dan Harjoto (2012) mendukung teori pemangku kepentingan, yaitu menemukan bahwa pertanggungjawaban lingkungan perusahaan merupakan perpanjangan tata kelola yang efektif, menjamin keberlanjutan perusahaan dengan praktik bisnis yang akuntabel dan transparan, memenuhi kepentingan tidak hanya pemegang saham namun seluruh pemangku kepentingan. Pertanggungjawaban lingkungan yang dilakukan perusahaan merupakan salah satu perwujudan pemenuhan kepentingan pemangku kepentingan. Hubungan positif antara tata kelola perusahaan yang efektif dan pertanggungjawaban lingkungan berdampak pada peningkatan nilai perusahaan. Pertanggungjawaban lingkungan dianggap dapat memitigasi konflik kepentingan antara manajer dan pemangku kepentingan; pertanggungjawaban lingkungan dianggap sebagai perangkat resolusi konflik kepentingan yang terjadi di perusahaan (stakeholder theorybased conflict resolution explanation) sehingga berdampak positif pada nilai perusahaan. Tata kelola perusahaan yang baik akan cenderung melakukan pertanggungjawaban lingkungan (Rao dkk., 2012) sehingga dapat mengurangi konflik kepentingan yang terjadi dalam perusahaan (Shleifer dan Vishny, 1997) yang kemudian akan berdampak pada nilai perusahaan (Tsamenyi dkk., 2007).
H. $_{6}$ Pertanggungjawaban lingkungan perusahaan memediasi hubungan antara tata kelola dan nilai perusahaan.

\section{METODE PENELITIAN}

Sampel penelitian ini adalah seluruh perusahaan sektor pertambangan dan top 50 sektor manufaktur (berdasarkan kapitalisasi pasar) yang terdaftar di Bursa Efek Indonesia periode 2013. Kedua sektor ini dipilih karena sektor pertambangan dan manufaktur dianggap sektor yang paling sensitif lingkungan.

Data penelitian diperoleh dari database OSIRIS, laporan tahunan, laporan berkelanjutan, dan website perusahaan. Tata kelola perusahaan (CG) yang diuji dalam penelitian ini adalah konsentrasi kepemilikan dan kualitas audit. Konsentrasi kepemilikan (OWNCON) diukur dari rasio saham yang dimiliki oleh pemegang saham terbesar sebagai proporsi total saham yang terdaftar di bursa saham (Ghazali, 2007). Kualitas audit (AUDIT) diukur dengan banyaknya anggota komite audit independen dalam suatu perusahaan.

Analisis konten laporan tahunan, laporan berkelanjutan, dan website perusahaan dilakukan berdasarkan GRI 4 guidelines untuk memperoleh data pertanggungjawaban lingkungan (EI). Penelitian ini hanya menggunakan 34 items checklist, yaitu items yang masuk dalam kategori lingkungan (EN1 - EN34). Apabila items informasi dalam guideline tidak diungkapkan dalam laporan keuangan maka diberi skor 0 , namun jika item informasi tersebut tersedia dalam laporan keuangan maka diberi skor 1 . Indeks pertanggungjawaban lingkungan setiap perusahaan dihitung dengan menjumlahkan keseluruhan nilai yang diperoleh setiap perusahaan.

Nilai perusahaan(Q) diukur menggunakan rasio Tobin's $Q$. Pengukuran Tobin's $Q$ mengikuti penelitian sebelumnya (Chung dan Pruitt, 1994) dan disesuaikan dengan kondisi di Indonesia (Darmawati dan Rika, 2005). 
Hipotesis dalam penelitian ini diuji menggunakan uji regresi berganda dengan sebelumnya dilakukan pengujian asumsi klasik (uji normalitas residual, uji heterokedastisitas, dan uji multikolinearitas). Untuk menguji hipotesis, penelitian ini menggunakan causal steps (Baron dan Kenny, 1986) dengan mengestimasi tiga persamaan regresi sebagai berikut:

$$
\begin{aligned}
& E I=i_{1}+a C G+\varepsilon_{1} \quad \ldots \ldots \ldots \ldots \ldots \ldots 1 \\
& Q=i_{2}+c C G+\varepsilon_{2} \quad \ldots \ldots \ldots \ldots \ldots \ldots \ldots . . .2 \\
& Q=i_{3}+c^{\prime} C G+b E I+\varepsilon_{3} \ldots \ldots \ldots \ldots \ldots . .3
\end{aligned}
$$

Terdapat beberapa kondisi yang harus terpenuhi untuk tercapainya mediasi (Baron dan Kenny, 1986), yaitu:

a. Tata kelola perusahaan (CG) harus mempengaruhi pertanggungjawaban lingkungan (EI) pada persamaan $(1)(a \neq 0)$.

b. Tata kelola perusahaan (CG) harus mempengaruhi nilai perusahaan (Q) pada persamaan $(2)(c \neq 0)$.

c. Pertanggungjawaban lingkungan (EI) harus mempengaruhi nilai perusahaan (Q) pada persamaan $(3)(b \neq 0)$.

Jika kondisi tersebut telah terpenuhi sesuai dengan arah yang diprediksi, efek tata kelola perusahaan pada nilai perusahaan pada persamaan (3) harus lebih rendah dibandingkan pada persamaan (2) (c'<c). Persamaan (1) dan (3) memperlihatkan bagaimana efek total tata kelola perusahaan pada nilai perusahaan terbagi menjadi efek langsung tata kelola perusahaan pada nilai perusahaan dan efek mediasi dimana tata kelola secara tidak langsung mempengaruhi nilai perusahaan melalui pertanggungjawaban lingkungan (MacKinnon, 2011). Complete mediation terjadi jika efek total secara penuh dijelaskan oleh mediator (pertanggungjawaban lingkungan), tidak terdapat efek langsung tata kelola perusahaan pada nilai perusahaan. Partial mediation terjadi jika hubungan antara tata kelola perusahaan dan nilai perusahaan tidak sepenuhnya terjadi karena adanya pertanggungjawaban lingkungan sebagai variabel mediasi.

HASIL PENELITIAN DAN PEMBAHASAN

Tabel 1

Hasil Analisis Regresi Hipotesis 1 dan 2 (Model 1)

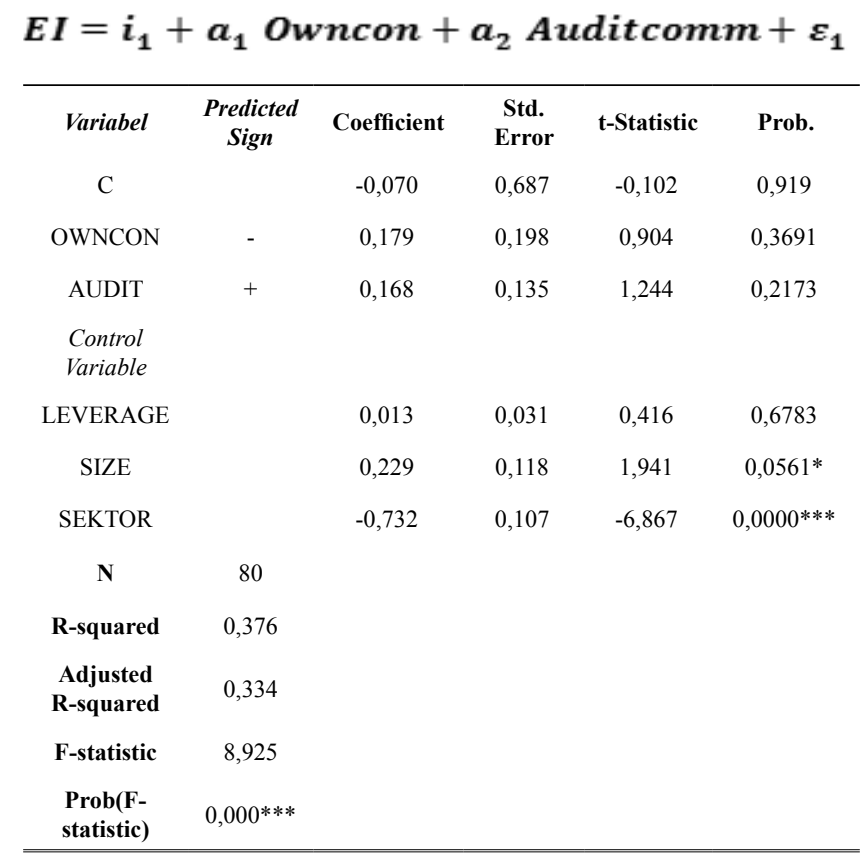

$\overline{\text { OWNCON adalah konsentrasi kepemilikan, yaitu }}$ persentase saham yang dimiliki pemegang saham terbesar. AUDIT adalah jumlah anggota komite audit indenpenden perusahaan. LEVERAGE adalah rasio total utang terhadap total ekuitas. SIZE adalah ukuran perusahaan yang dihitung menggunakan logaritama natural kapitalisasi pasar (transformasi logaritma). SEKTOR adalah dummy variabel, 1 untuk perusahaan sektor manufaktur dan 0 untuk perusahaan sektor pertambangan.

*** signifikan pada level 1\%

** signifikan pada level $5 \%$

* $\quad$ signifikan pada level $10 \%$

Sumber: hasil olah data

Hasil regresi model 1 menunjukkan koefisien variabel OWNCON dan AUDIT tidak signifikan $(0,3691$ dan 0,2173). Tidak 
signifikannya koefisien kedua variabel menunjukkan bahwa konsentrasi kepemilikan dan kualitas audit tidak mempengaruhi keputusan perusahaan melakukan pertanggungjawaban lingkungan. Struktur kepemilikan saham yang terkonsentrasi dan jumlah anggota audit independen tidak mempengaruhi keputusan perusahaan melakukan pertanggungjawaban lingkungan. Oleh karena itu hipotesis pertama dan kedua tentang pengaruh tata kelola perusahaan terhadap pertanggungjawaban lingkungan tidak terdukung.

Tabel 2

Hasil Analisis Regresi Hipotesis 3 dan 4 (Model 2)

\section{$Q=i_{2}+c_{1}$ Owncon $+c_{2}$ Auditcomm $+\varepsilon_{2}$}

\begin{tabular}{cccccc}
\hline Variabel & $\begin{array}{c}\text { Predicted } \\
\text { Sign }\end{array}$ & Coefficient & $\begin{array}{c}\text { Std. } \\
\text { Error }\end{array}$ & t-Statistic & Prob. \\
C & & $-1,075$ & 0,351 & $-3,066$ & $0,003^{* * *}$ \\
OWNCON & - & 0,07 & 0,145 & 0,482 & 0,6319 \\
AUDIT & + & 0,002 & 0,076 & 0,024 & 0,9811 \\
Control Variable & & & & & \\
LEVERAGE & & $-0,048$ & 0,028 & $-1,71$ & $0,0913^{*}$ \\
SIZE & & 0,2023 & 0,060 & 3,368 & $0,0012^{* * *}$ \\
SEKTOR & & 0,12 & 0,072 & 1,67 & $0,0992^{*}$ \\
N & 80 & & & & \\
R-squared & 0,260 & & & & \\
Adjusted & 0,210 & & & & \\
R-squared & & & & & \\
F-statistic & 5,201 & & & & \\
Prob(F-statistic) & $0,000^{* * *}$ & & & & \\
\hline \hline
\end{tabular}

OWNCON adalah konsentrasi kepemilikan, yaitu persentase saham yang dimiliki pemegang saham terbesar. AUDIT adalah jumlah anggota komite audit indenpenden perusahaan. LEVERAGE adalah rasio total utang terhadap total ekuitas. SIZE adalah ukuran perusahaan yang dihitung menggunakan logaritama natural kapitalisasi pasar (transformasi logaritma). SEKTOR adalah dummy variabel, 1 untuk perusahaan sektor manufaktur dan 0 untuk perusahaan sektor pertambangan.
*** signifikan pada level $1 \%$

** $\quad$ signifikan pada level $5 \%$

* $\quad$ signifikan pada level 10\%

Sumber: hasil olah data

Hasil regresi tabel 2 menunjukkan tidak adanya pengaruh konsentrasi kepemilikan dan kualitas audit terhadap nilai perusahaan. Tidak adanya pengaruh ini ditunjukkan dengan koefisien kedua variabel yang tidak signifikan $(0,6319$ dan 0,9811), sehingga hipotesis 3 dan 4 tidak terdukung. Tidak adanya pengaruh konsentrasi kepemilikan pada keputusan pertanggungjawaban lingkungan dan nilai perusahaan dapat dijelaskan dari penelitian Demsetz dan Villalonga (2001). Dalam penelitiannya, mereka menjelaskan bahwa struktur kepemilikan suatu perusahaan merupakan hasil dari keputusan yang mencerminkan pengaruh pemegang saham dan perdagangan di pasar, sehingga sebenarnya tidak ada hubungan sistematik antara variasi struktur kepemilikan (terkonsentrasi maupun tersebar) dengan variasi nilai perusahaan, begitu pula dengan keputusan perusahaan melakukan pertanggungjawaban lingkungan. Argumen baik terkonsentrasi maupun tersebar, tujuan perusahaan adalah untuk memaksimalkan kepentingan (kemakmuran) pemegang saham, salah satunya adalah meningkatkan nilai perusahaan, baik dengan melakukan pertanggungjawaban lingkungan maupun tidak juga dapat menjelaskan tidak adanya pengaruh konsentrasi kepemilikan pada pertanggungjawaban lingkungan dan nilai perusahaan.

Pedoman Umum Good Governance Indonesia telah mengatur keberadaan auditor independen dalam komite audit independen, sehingga pasar Indonesia tidak merespon informasi terkait keberadaan auditor independen karena dianggap tidak relevan. Hal ini jugalah yang bisa menjadi penjelasan rasional mengapa kualitas audit tidak mampengaruhi keputusan pertanggungjawaban lingkungan perusahaan. 
Tabel 3

Hasil Analisis Regresi Hipotesis 5 dan 6 (Model 3)

$$
Q=i_{3}+c_{1}^{\prime} \text { Owncon }+c_{2}^{\prime} \text { Auditcomm }+b E I+\varepsilon_{3}
$$

\begin{tabular}{cccccc}
\hline Variabel & $\begin{array}{c}\text { Predicted } \\
\text { Sign }\end{array}$ & Coefficient & Std. Error & t-Statistic & Prob. \\
C & & $-1,085$ & 0,344 & $-3,153$ & $0,0023^{* * *}$ \\
OWNCON & - & 0,095 & 0,143 & 0,666 & 0,5078 \\
AUDIT & + & 0,026 & 0,075 & 0,341 & 0,7344 \\
EI & + & 0,142 & 0,072 & 0,961 & $0,0537^{*}$ \\
Control Variable & & & & & \\
LEVERAGE & & $-0,048$ & 0,028 & $-1,677$ & $0,0978^{*}$ \\
SIZE & & 0,2023 & 0,061 & 3,834 & $0,0003^{*} * *$ \\
SEKTOR & & 0,12 & 0,088 & 0,183 & 0,8554 \\
N & 80 & & & & \\
R-squared & 0,297 & & & & \\
$\begin{array}{c}\text { Adjusted } \\
\text { R-squared }\end{array}$ & 0,239 & & & & \\
F-statistic & 5,141 & & & & \\
$\begin{array}{c}\text { Prob(F- } \\
\text { statistic) }\end{array}$ & $0,000^{* * *}$ & & & & \\
\hline \hline ONNCON & adalah & & & & \\
\hline
\end{tabular}

OWNCON adalah konsentrasi kepemilikan, yaitu persentase saham yang dimiliki pemegang saham terbesar. AUDIT adalah jumlah anggota komite audit indenpenden perusahaan. EI adalah angular indeks pertanggungjawaban lingkungan berdasarkan GRI G4 Guidelines (transformasi arcsin). LEVERAGE adalah rasio total utang terhadap total ekuitas. SIZE adalah ukuran perusahaan yang dihitung menggunakan logaritama natural kapitalisasi pasar (transformasi logaritma). SEKTOR adalah dummy variabel, 1 untuk perusahaan sektor manufaktur dan 0 untuk perusahaan sektor pertambangan.

*** signifikan pada level $1 \%$

** signifikan pada level $5 \%$

* signifikan pada level 10\%

Sumber: hasil olah data

Tabel 3 menunjukkan bahwa pertanggungjawaban lingkungan terbukti mempengaruhi nilai perusahaan $(0,0537)$, sehingga hipotesis 5 terdukung. Hasil ini mendukung teori pemangku kepentingan dan teori legitimasi bahwa pertanggungjawaban lingkungan yang dilakukan perusahaan merupakan bentuk perwujudan pemenuhan kepentingan seluruh pemangku kepentingan dan agar memperoleh dukungan dan legitimasi dari masyarakat. Hubungan mediasi tata kelola perusahaan, pertanggungjawaban lingkungan, dan nilai perusahaan tidak dapat diuji karena tidak terpenuhinya syarat hubungan mediasi, yaitu tidak adanya pengaruh tata kelola perusahaan pada pertanggungjawaban lingkungan dan nilai perusahaan, sehingga hipotesis 6 tidak terdukung. Hal ini menunjukkan bahwa di Indonesia, pertanggungjawaban lingkungan belum bisa menjadi pemitigasi konflik kepentingan yang terjadi di perusahaan.

\section{KESIMPULAN DAN SARAN}

\section{Kesimpulan}

Penelitian ini membuktikan bahwa pertanggungjawaban lingkungan yang dilakukan perusahaan mempengaruhi nilai perusahaan terkait. Hal ini sesuai dengan teori pemangku kepentingan, yaitu perusahaan melakukan pertanggungjawaban lingkungan sebagai usahanya memenuhi kepentingan seluruh pemangku kepentingan; serta teori legitimasi, yaitu perusahaan melakukan pertanggungjawaban lingkungan sebagai bentuk perwujudan kontrak social perusahaan dengan lingkungan sekitar. Penelitian ini juga membuktikan bahwa pola hubungan tidak langsung antara tata kelola perusahaan, pertanggungjawaban lingkungan, dan nilai perusahaan yang ada di negara maju (Jo dan Harjoto, 2012), tidak ada di negara berkembang (Indonesia). Di Indonesia, pertanggungjawaban lingkungan belum mampu menjadi perantara dan belum dapat memitigasi konflik kepentingan yang ada di perusahaan. 


\section{Saran}

Penelitian selanjutnya dapat menguji hubungan langsung dan tidak langsung ini menggunakan variabel tata kelola perusahaan yang lain. Penelitian selanjutnya juga dapat mempertimbangkan pertanggungjawaban sosial dan lingkungan lainnya dalam GRI yang belum dipertimbangkan dalam penelitian ini.

\section{DAFTAR PUSTAKA}

Al-Tuwaijri, S. A., Christensen, T. E., \& Hughes, K. . (2004). The relations among environmental disclosure, environmental performance, and economic performance: a simultaneous equations approach. Accounting, Organizations and Society, 29(5-6), 447-471.

Baron, R. M., \& Kenny, D. a. (1986). The moderator-mediator variable distinction in social psychological research: Conceptual, strategic, and statistical considerations. Journal of Personality and Social Psychology, 51(6), 11731182.

Camfferman, K., \& Cooke, T. E. (2002). An analysis of disclosure in the annual reports of U.K and Dutch Companies. Journal of International Accounting Research, 1(1), 3-30.

Choi, F. D. S. (2003). International Finance and Accounting Handbook (Third Edition) (p. 24.3).

Chung, K. H., \& Pruitt, S. W. (1994). A simple approximation of tobin's q. Financial Management, 23(3), 70-74.

Darmawati, K., \& Rika, G. R. (2005). Hubungan Corporate Governance dan Kinerja Perusahaan. Jurnal Riset Akuntansi Indonesia, 70, 135-150.
Demsetz, H., \& Villalonga, B. (2001). Ownership structure and corporate performance. Journal of Corporate Finance, 7(3), 209-233.

Dey, A. (2008). Corporate Governance and Agency Conflicts. Journal of Accounting Research, 46(5), 1143-1181.

Donaldson, T., \& Preston, L. E. (1995). The Stakeholder Thepry of The Corporation: Concepts, Evidence, and Implications. The Academy of Management Review, 20(1), 65-91.

Freeman, R. E., \& Phillips, R. A. (2002). Stakeholder Theory: A Libertarian Defense. Business Ethics Quarterly, 12(3), 331-349.

Ghazali, N. A. M. (2007). Ownership structure and corporate social responsibility disclosure: some Malaysian evidence. Corporate Governance, 7(3), 251-266.

Haniffa, R. M., \& Cooke, T. E. (2005). The impact of culture and governance on corporate social reporting. Journal of Accounting and Public Policy, 24(5), 391-430.

Haposoro, D. (2012). Pengaruh corporate governance dan kualitas audit terhadap pengungkapan corporate social responsibility. Jurnal Akuntansi \& Manajemen (JAM), 23(3), 199-215.

Holder-webb, L., Cohen, J. R., Nath, L., \& Wood, D. (2009). The Supply of Corporate Social Responsibility Disclosures Among U.S. Firms. Journal of Business Ethics, 84(4), 497-527.

Jensen, M. C., \& Meckling, W. H. (1976). Theory of the Firm: Managerial Behavior, Agency Costs and Ownership Structure. Journal of Financial Economics, 3(4), 305-360.

Jo, H., \& Harjoto, M. a. (2011). Corporate Governance and Firm Value: The Impact 
of Corporate Social Responsibility. Journal of Business Ethics, 103(3), 351-383.

Jo, H., \& Harjoto, M. a. (2012). The Causal Effect of Corporate Governance on Corporate Social Responsibility. Journal of Business Ethics, 106(1), 53-72. http:// doi.org/10.1007/s10551-011-1052-1

Jones, T. M. (1995). Instrumental Stakeholder Theory: A Synthesis of Ethics and Economics. The Academy of Management Review, 20(2), 404-437.

Klein, A. (2002). Audit Committee, Board of Director Characteristics, and Earnings Management. Journal of Accounting and Economics, 33(3), 375-400.

KNKG. (2006). Pedoman Umum Good Corporate Governance Indonesia.

La Porta, R., Lopez-de-Silanes, F., \& Shleifer, A. (1999). Corporate Ownership Around the World. The Journal of Finance, 54(2), 471-517.

Lakhal, F. (2005). Voluntary Earnings Disclosures and Corporate Governance: Evidence from France. Review of Accounting and Finance, 4(3), 64-85.

MacKinnon, D. P. (2011). Integrating Mediators and Moderators in Research Design. Res Soc Work Pract, 21(6), 675-681.

Malik, M. (2014). Value-Enhancing Capabilities ofCSR:ABrief Review of Contemporary Literature. Journal of Business Ethics, 127(2), 419-438.

McMullen, D. A., \& Raghunandan, K. (1996). Enhancing audit committee effectiveness. Journal of Accountancy, 182(2), 79.

Moser, D. V., \& Martin, P. R. (2012). A Broader Perspective on Corporate Social Responsibility Research in Accounting. The Accounting Review, 87(3), 797-806.
Rao, K. K., Tilt, C. A., \& Lester, L. H. (2012). Corporate governance and environmental reporting: an Australian study. Corporate Governance: The International Journal of Business in Society, 12(2), 143-163. 2

Said, R., Hj Zainuddin, Y., \& Haron, H. (2009). The relationship between corporate social responsibility disclosure and corporate governance characteristics in Malaysian public listed companies. Social Responsibility Journal, 5(2), 212-226.

Shleifer, A., \& Vishny, R. W. (1997). A Survey of Corporate Governance. The Journal of Finance, 52(2), 737-783.

Siagian, F., Siregar, S. V., \& Rahadian, Y. (2013). Corporate governance, reporting quality, and firm value: evidence from Indonesia. Journal of Accounting in Emerging Economies, 3(1), 4-20.

Siallagan, H., \& Machfoedz, M. (2006). Mekanisme Corporate Governance, Kualitas Laba dan Nilai Perusahaan. Simposium Nasional Akuntansi, 9.

Spitzeck, H. (2009). The development of governance structures for corporate responsibility. Corporate Governance: The International Journal of Business in Society, 9(4), 495-505.

Tsamenyi, M., Enninful-Adu, E., \& Onumah, J. (2007). Disclosure and corporate governance in developing countries: evidence from Ghana. Managerial Auditing Journal, 22(3), 319-334.

Wright, D. W. (1996). Evidence on The Relation Between Corporate Governance Characteristics and The Quality of Financial Reporting. 